Sharif University of Technology
Scientia Iranica
SCIENTIA $\quad \begin{gathered}\text { Transactions D: Computer Science \& Engineering and Electrical Engineering } \\ \text { w }\end{gathered}$

\title{
A novel time varying dynamic modeling for hysteresis
} motor

\author{
A. Halvaei Niasar* \\ Department of Electrical and Computer Engineering, University of Kashan, Kashan, P.O. Box 87317-51167, Iran. \\ Received 8 September 2015; received in revised form 8 March 2016; accepted 10 May 2016
}

\section{KEYWORDS \\ Dynamic modeling; \\ Hysteresis motor; \\ Simulation; \\ Transient; \\ Circumferential-flux.}

\begin{abstract}
Hysteresis motors are used in special applications such as gyroscope and gas centrifuge due to their unique features such as synchronism, self-starting, and developing smooth torque. Dynamic modeling of hysteresis motors is essential to the prediction of the transient performance, the study of the dynamic stability, the development of modern closed-loop control, and the estimation strategies. This paper develops a new time varying dynamic model for a high-speed, circumferential-flux type hysteresis motor, in which the parameters of equivalent circuit of rotor's material are adjusted based on operational $B-H$ loop. For this purpose and based on the elliptical assumption about $B-H$ loops, the hysteresis lag angle, $\beta$, is updated due to the applied stator voltage and available load torque. Developed mathematical model satisfies many theoretical aspects of hysteresis motor behavior in transient and steady-state situations. The model offers a tool to study the start-up of hysteresis motor, the change of stator voltage, the variation of load torque, the frequency tracking of variable-speed applications, and transient-state response to design parameters. Some simulations are provided to demonstrate the validity of developed model in Matlab/Simulink and are verified by some experimental results. The proposed results verify the advantages of this model over previous research works.

(C) 2017 Sharif University of Technology. All rights reserved.
\end{abstract}

\section{Introduction}

The hysteresis motor is a well-known synchronous motor that is often used in special small power applications. It is a self-starting motor that has some unique advantages over other synchronous motors. It has constant synchronizing torque and is able to synchronize any inertia load coupled to it. The starting current of hysteresis motor is limited and is usually less than $180 \%$ of the rated-load current [1] Developed torque of hysteresis motor is very smooth in which it has the lowest noise and vibration among other electrical motors. These advantages make the hysteresis motor suitable for small power adjustablespeed applications requiring much smooth torque at

*. Tel.: +983155912412

E-mail address: halvaei@kashanu.ac.ir high speeds such as navigation gyroscopes and gas centrifuges. However, the hysteresis motor has some deficiencies, including poor power factor which is less than 0.5, small power/torque, low efficiency, and high cost of hysteresis rotor material [2].

The manufacturing of hysteresis motors is simple and is similar to induction motors in terms of its structure. There are two main structures of hysteresis motors: cylindrical and disk types [3,4]. Cylindrical hysteresis motors have the rotor shaped as an annular ring and supported by a perpendicular cylindrical shaft and the air gap flux is radial. Disk type hysteresis motors have a thin disk as rotor and the air gap flux is axial [5-7]. Cylindrical hysteresis motors are classified into two types of circumferential-flux and radialflux [8]. In circumferential-flux hysteresis motor, the rotor ring is mounted on non-magnetic material as support. The magnetic field lines in the rotor are mostly 


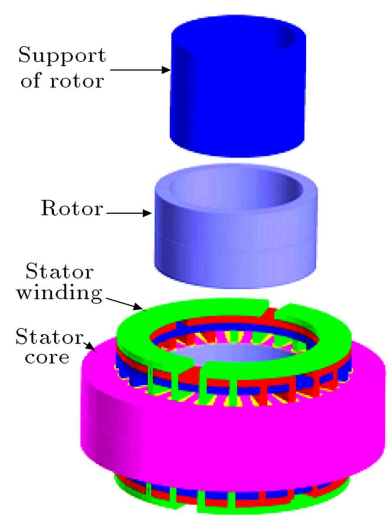

(a)

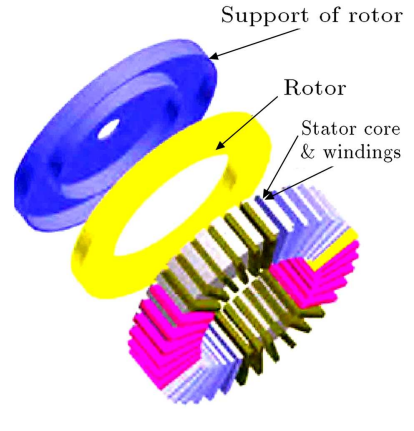

(b)
Figure 1. Structure of various types of hysteresis motor: (a) Circumferential-flux and (b) axial-flux [5].

circumferential to the ring. This type of hysteresis motor is mostly used in industrial applications [9]. Figure 1 shows the structure of a circumferential-flux and axial-flux (disk type) hysteresis motor.

In spite of easy operation and simple manufacturing of hysteresis motors, the analysis and modeling of this motor is more complicated than the Permanent Magnet Synchronous Motors (PMSMs) and Induction Motors (IMs) due to nonlinearity of rotor magnetic material. For PMSMs, the magnet of rotor is modeled with a constant flux source, and for IMs, the $B-H$ loop of rotor is assumed linear and hysteresis loss of power of rotor is just considered in efficiency calculations. However, hysteresis motor operates based on hysteresis property of the semi-hard magnetic material used in the rotor [2]. As shown in Figure 2, the width of $B-H$

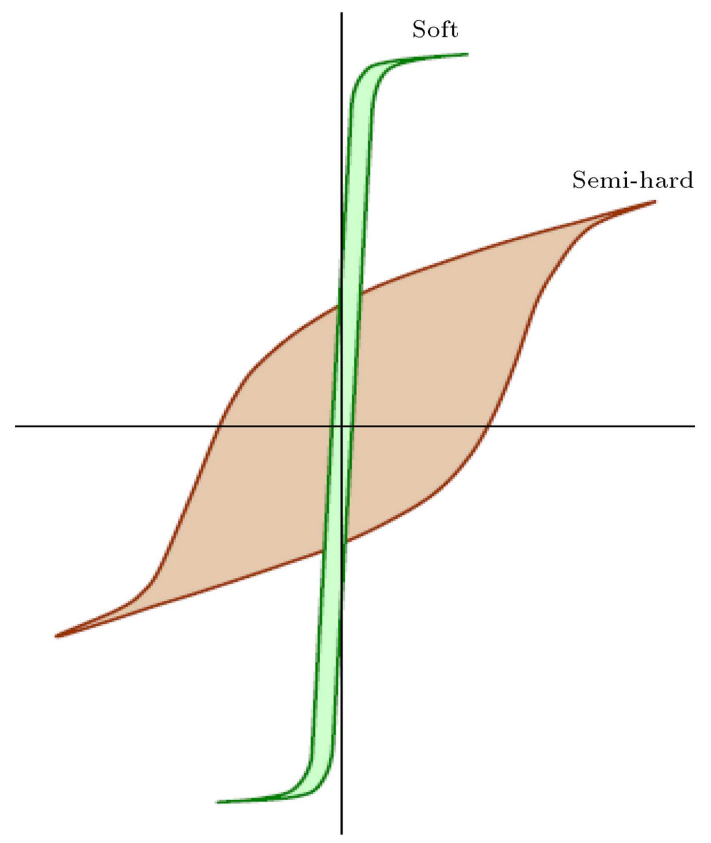

Figure 2. Comparison between $B-H$ characteristics of soft and semi-hard magnetic materials [14].

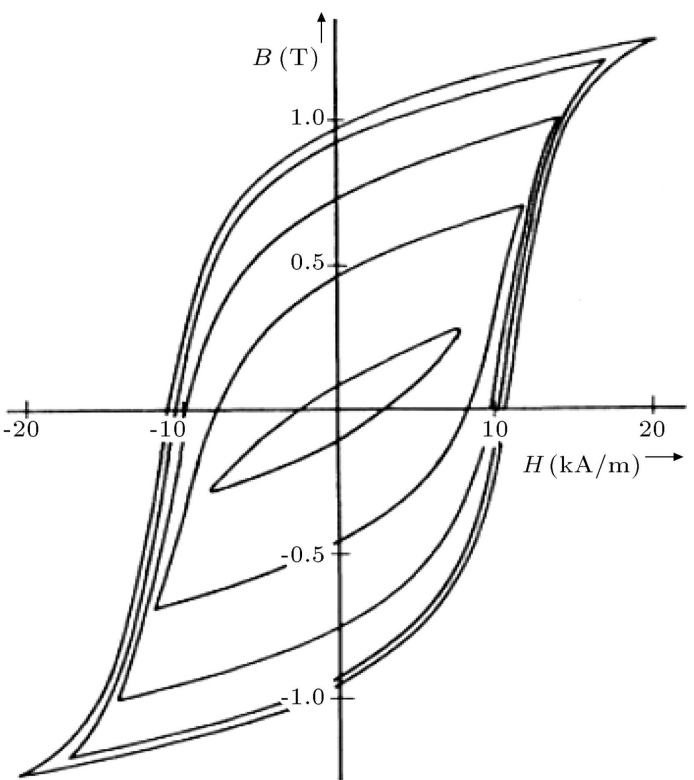

Figure 3. $B-H$ characteristics for a typical vicalloy magnetic material used in hysteresis motor [15].

loop in semi-hard material is wider than that of the soft magnetic materials used in IMs and cannot be considered linear $[10,11]$. Moreover, with variations of stator voltage in adjustable-speed drives [12] or under changing the load torque [13], the $B-H$ loops of the rotor change. Figure 3 shows a set of $B-H$ loops of Vicalloy material used in rotor of hysteresis motors [15]. To analyze the performance of motor and to develop an equivalent circuit, nonlinear $B-H$ curves of the rotor's material should be modeled in the right manner.

The steady-state equivalent circuit and the analysis of hysteresis motor have been well established by many authors. The major contribution was made by Teare [16] who published a method of calculating torque on the known field configurations of magnetic flux and magneto motive force in the hysteresis material based on elliptical approximation. Further extended studies based on elliptical representation were carried out by Roters [2], Miyari and Kataoka [17] and Robertson and Zaky [18]. Copeland and Slemon presented an analytical study of both circumferential and radial types of hysteresis motors and introduced the idea of using the fundamental developed torque in terms of motor dimensions and hysteresis material characteristics $[19,20]$. They developed a steady-state model based on approximations of representing the hysteresis loop by rectangular, and then parallelogram curves. Afterwards, Rahman extended the steady-state modeling of hysteresis motor based on parallelogram approximation in synchronous and sub-synchronous modes $[15,21]$. The common point in all mentioned steady-state equivalent circuit models is that the rotor's hysteresis loop is considered hysteresis resistance, 


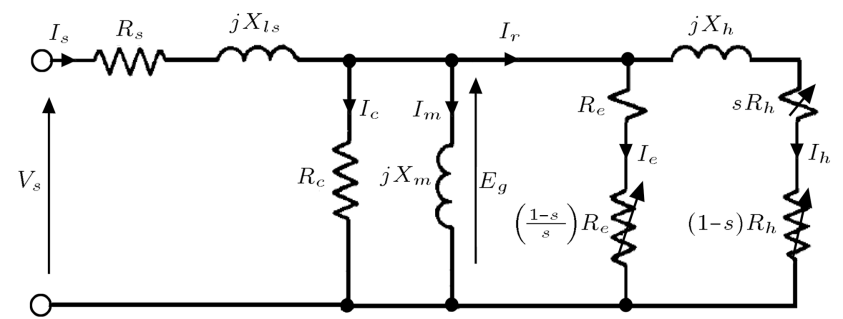

Figure 4. Equivalent circuit of hysteresis motor at sub synchronous mode [21].

$R_{h}$, in series with reactance, $X_{h}$, in sub synchronous mode as shown in Figure 4.

In the other way, transient performance prediction and dynamic modeling of hysteresis motor are quite important to optimum design and stability analysis of hysteresis motor. Moreover, in variable-speed applications of hysteresis motors using modern control techniques, accurate dynamic model is required. Also, for sensorless closed-loop control of hysteresis motor [22], estimation of the rotor's speed/position using observers and estimators requires an exact and reliable dynamic model [23]. In spite of the steadystate model of hysteresis motor, the dynamic modeling of this motor has fewer contributions and reports. Even some models cannot satisfy the basic principles of hysteresis motor theory. For example, in some motors, there are underloading and gradual decline of the speed, whereas hysteresis motor is a synchronous one. Some authors have used fixed impedance in rotor's circuit when the load changes while the $B-H$ curve alters and the rotor impedance should change.

This paper develops a linear time varying dynamic model for a circumferential-flux hysteresis motor to predict the performance of motor in transient and steady-state conditions. In the proposed model, equivalent circuit of rotor is adapted by variation of stator voltage and torque. The paper is organized as follows: In Section 2, all previous dynamic models of hysteresis motor are studied briefly and their characteristics are investigated. Afterwards, in Section 3, developed dynamic model is presented. In Section 4, some simulation results are given under load variations, stator voltage variations, and speed reference tracking, and finally, conclusion is explored in Section 5.

\section{Study of previous proposed dynamic model for hysteresis motor}

As mentioned earlier, there has been little contribution in the literature to dynamic modeling of hysteresis motors. The basic concept used in dynamic models of hysteresis motor comes from steady-state models. In previous models, a constant magnetizing reactance in air gap is considered and rotor is modeled with impedance. The difference between various models comes from how they produce models of the rotor. The reported dynamic modeling techniques can be classified into 4 groups: modeling based on constant impedance for rotor, modeling based on variable resistance, modeling based on variable impedance, and modeling based on variable impedance and voltage source in rotor's circuit. In this section, the proposed dynamic models are briefly investigated.

\subsection{Modeling based constant impedance}

In this manner, $B-H$ loop of the rotor's magnetic material is assumed to be as elliptical shape, and so, the rotor is to be modeled on with inductive impedance. Reported models have just considered major $B-H$ loop of rotor that is related to nominal stator voltage [24]. The main problem of this modeling method is the presence of speed slip under load variations, whereas this motor is of synchronous type. As the load torque increases, the motor's speed falls. So, this model really belongs to an induction motor, and cannot be true for hysteresis motor.

\subsection{Modeling based on variable resistance}

This modeling method was developed by Rahman and was linearized to study the dynamic stability of hysteresis motor for small-scale disturbances [1]. However, in the presented simulation results, the transient performance of motor under load was not simulated. The reported variation of slip that leads to zero in steady-state was carried under no-load condition. Although, the authors have mentioned that the effective resistance representing the hysteresis power $\left(R_{h}\right)$ is slip-dependent during run-up mode, and it is assumed to be constant at synchronous speed and quasi-static at other speeds. But, there is not any variable resistance in the equations. Moreover, it refers to induced voltage caused from magnetic material of rotor $\left(E_{p}\right)$ while it is absent in the KVL equations.

Another study was carried out by Rahman for dynamic modeling of Permanent-magnet Hysteresis Synchronous Motor (PHMS) [25,26]. Theoretically, the only difference between PMHS and hysteresis motors comes from the magnet on the rotor in PMHS motor. It seems that with neglecting dependent current source $\left(i_{\mathrm{PM}}\right)$ related to $\mathrm{PM}$, dynamic equivalent circuit of hysteresis motor in [1] is derived. We have simulated the developed model by [1], and we believe that this dynamic model cannot predict the transient performance of hysteresis motor, and consequently is not correct for all conditions.

\subsection{Modeling based on variable impedance}

This modeling method was proposed by Nitao in [4], in which they developed a dynamic model for hysteresis motor in stationary $d q$ coordinates based on the model by Miyairi and Kataoka [17]. In the proposed work, the resistance and reactance related to $B-H$ curve 
are considered with respect to load angle $(\delta)$ as:

$$
\begin{aligned}
& R_{h r}=\omega_{b} \frac{m K_{\omega}^{2} N_{\omega}^{2} V_{r} \mu}{\pi^{2} r_{r}^{2}} \sin \delta, \\
& L_{h r}=\frac{m K_{\omega}^{2} N_{\omega}^{2} V_{r} \mu}{\pi^{2} r_{r}^{2}} \cos \delta,
\end{aligned}
$$

where the load angle, $\delta$, obeys the following equation:

$$
\frac{d \delta}{d t}=\left(\frac{2}{P}\right)(s)=\left(\frac{2}{P}\right)\left(\omega_{b}-\omega_{r}\right) .
$$

Subject to the condition:

$$
|\delta| \leq \delta_{\max }
$$

' $s$ ' represents the motor slip. Actually, they considered hysteresis lag angle $(\beta)$ equal to load angle or slip position $(\delta)$, and $\delta_{\max }$ was considered $40^{\circ}$. This approximation yields an adaptive impedance for rotor modeling as a function of load, but there are some challenges in the presented simulation results. Figure 5 shows the electrical equivalent circuit for dynamic modeling of hysteresis motor in $d q$ stationery reference frame presented in [4]. The rotor resistance $\left(R_{r}\right)$ in this circuit is $R_{r} \| R_{e}$, that $R_{e}$ represents the eddy current resistance.

Some simulation results of neglecting eddy current effect are shown in Figure 6. During acceleration mode, developed torque is constant, and then oscillates after reaching synchronism which is questionable. Although hysteresis motor is a dynamic system, the torque is perfectly constant during acceleration. Other variables also have the same behavior. The authors in [4] mentioned that the oscillations are the hunting phenomena of hysteresis motor and are due to insufficient damping of the rotor. Another dubious result is that with constant stator voltage, stator current increases after the motor reaches synchronous speed.
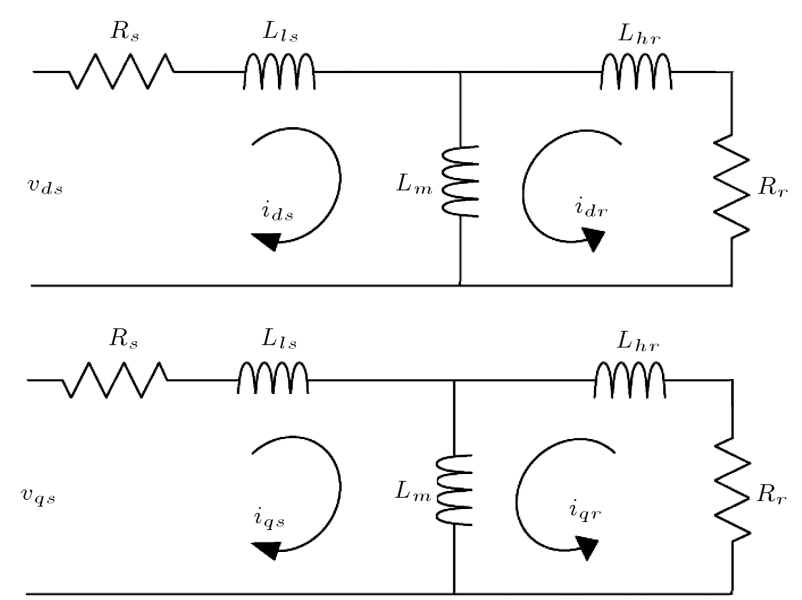

Figure 5. The electrical equivalent circuits of the hysteresis motor in [4].
The proposed modeling technique was successful, in that it makes the motor reach synchronism under load variations and is able to modify the rotor's equivalent impedance with lag angle. This method cannot be used for other hysteresis motors with different parameters. Some other hysteresis motors with $\delta_{\max }<$ $90^{\circ}$ were simulated, but the motors under load torque cannot reach synchronism. For this purpose, $\delta_{\max }$ was increased to $170^{\circ}$.

It should be noted that the hysteresis lag angle, $\beta$, caused by semi-hard magnetic material is between $30^{\circ} \sim 70^{\circ}$ for elliptical representation and $90^{\circ}$ for parallelogram representation $[1,4]$. So, the mentioned lag angle of $170^{\circ}$ is meaningless and false. The main deficiency of the presented model in [4] is that considering lag angle $(\delta)$ instead of torque angle $(\beta)$ cannot reflect the real behavior of hysteresis motor. For example, changing the $B-H$ curve when the input voltage varies, or changing the magnetic performance of the rotor cannot be included in the proposed dynamic model.

\subsection{Modeling based on variable impedance and voltage source}

This modeling method was presented by Darabi in $[27,28]$. In the proposed model, the hysteresis material of rotor can be replaced by two-phase balanced windings with the same number of turns of the stator in $d q$ reference frame, as shown in Figure 7 . The eddy current effect is modeled by resistance $R_{e}$, and hysteresis loss or power is represented by $R_{h}$. Parameter $\alpha$ is the angle between $d$ axis and phase ' $a$ ' axis of the stator, which is called hysteresis delay angle. Also, two induced voltages, $V_{d r}$ and $V_{q r}$, are considered in the rotor circuit for temporary magnet property due to hysteresis loop. The rotor resistance and reactance related to hysteresis loop are modeled as functions of delay angle $\alpha$ and can be obtained from structural parameters of disc type hysteresis motor as [28]:

$$
\begin{aligned}
R_{h} & =\frac{4 m f\left(K_{w} N_{p h}\right)^{2} t_{r}\left(R_{o}-R_{i}\right) K_{s f} B_{q}}{1000 R_{a v} H_{p}} \sin \alpha, \\
X_{r} & =\frac{R_{h}}{\tan \alpha} .
\end{aligned}
$$

The hysteresis delay angle $(\alpha)$ in above equations is related to hysteresis loops of rotor, and these loops depend on the stator voltage amplitude. Larger voltage amplitude leads to a wider $B-H$ loop and greater delay angle, and vice-versa. For calculation the real value of rotor parameters and magnetizing part, the operational delay angle $\alpha$ or hysteresis loop should be identified. For this purpose, an initial $B-H$ curve (or $B_{m}$ ) is chosen, and the stator voltage is calculated based on steady-state equivalent circuit, and then it is compared with the real stator voltage. The value of $B_{m}$ 


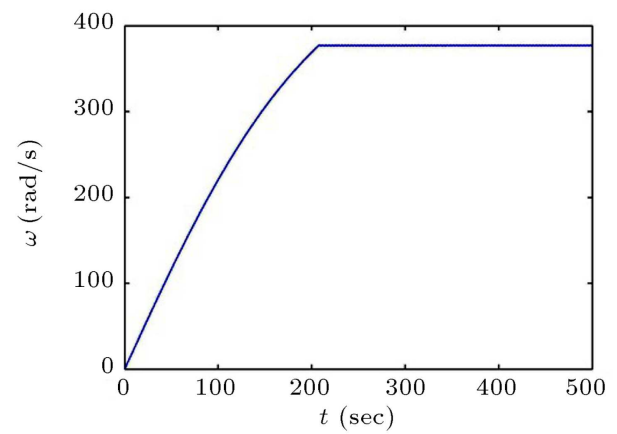

(a)

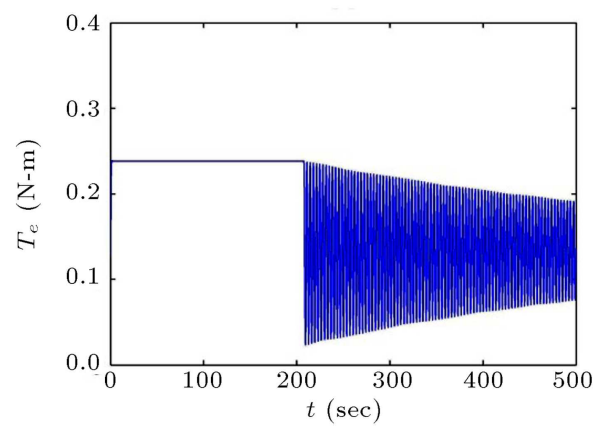

(c)

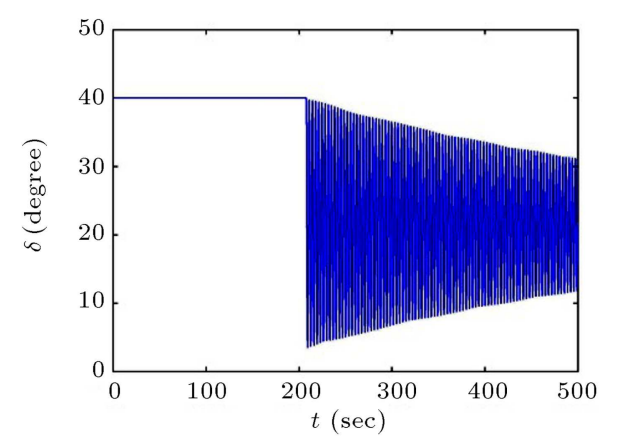

(b)

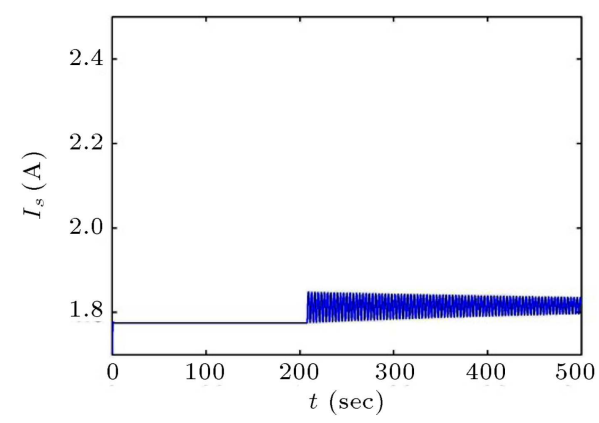

(d)

Figure 6. Simulation results of dynamic model of hysteresis motor neglecting eddy currents: (a) Motor speed, (b) lag angle, (c) electromagnetic torque, and (d) stator current [4].

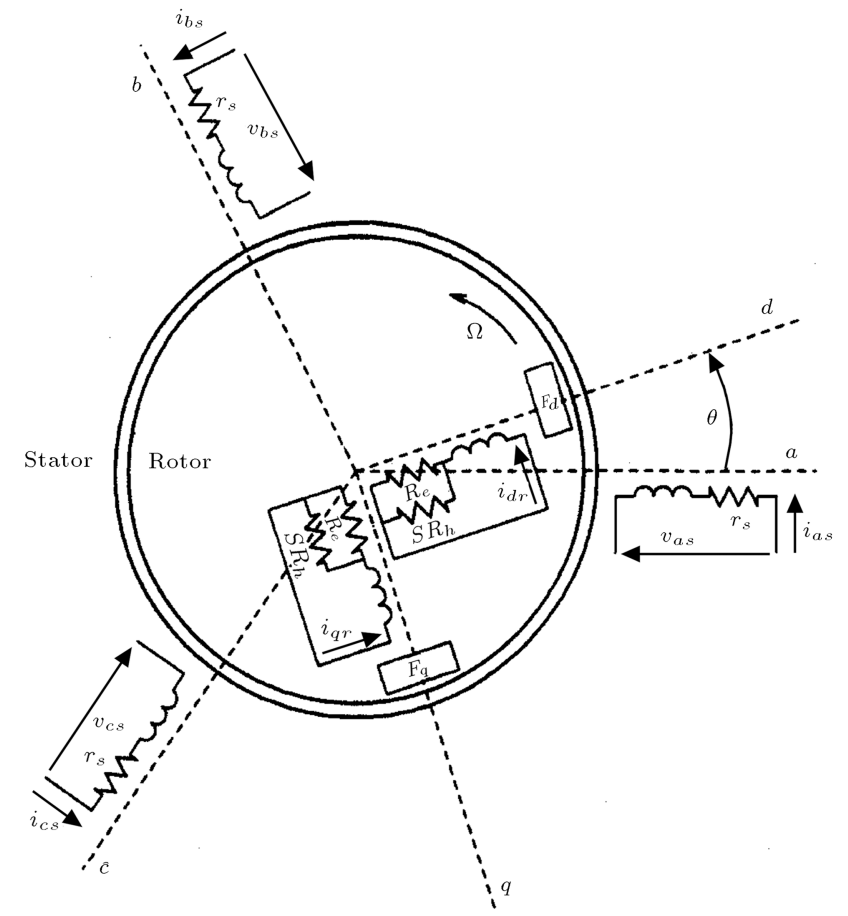

Figure 7. The Equivalent circuit of dynamic model schematic of hysteresis motor in [28].

is modified by a proper step size, and the procedure is repeated until the voltage difference falls into desired tolerance. The proposed simulation results in [28] indicate that the motor can reach synchronism under any sudden change in the load.

\section{The proposed novel dynamic model for hysteresis motor}

Among previous models, the modeling based on variable impedance and voltage source satisfies more aspects of hysteresis motor theory. However, this model and all earlier models cannot predict the operational $B-H$ loop or hysteresis lag angle, while the load torque changes. In other words, to calculate hysteresis resistance, $R_{h}$, they have used a constant hysteresis lag angle $[1,24]$ or varied with stator voltage [28]. In this section we develop, a new dynamic model for hysteresis motor incorporating the change of load torque and stator voltage to identify the operational $B-H$ loop of the rotor. Let us firstly investigate the magnetic state of the rotor during load torque changing.

\subsection{Magnetic behavior of rotor hysteresis material due to the load torque changing}

When the rotor turns at sub-synchronous speed, any point in the rotor hysteresis material experiences a sinusoidal variation of flux density, $B$, in time, and consequently a magnetic hysteresis loop, $L_{o}$, as shown in Figure $8(\mathrm{a})$. Other points in the rotor hysteresis material experience exactly the same hysteresis loop, displaced in time phase. Thus, the loop not only gives the time variation of the magnetic state at a point in the rotor, but also gives the space variation of magnetic state around rotor at a particular instant of time [13]. The area of this loop is proportional to output torque, $T_{e m}$. 


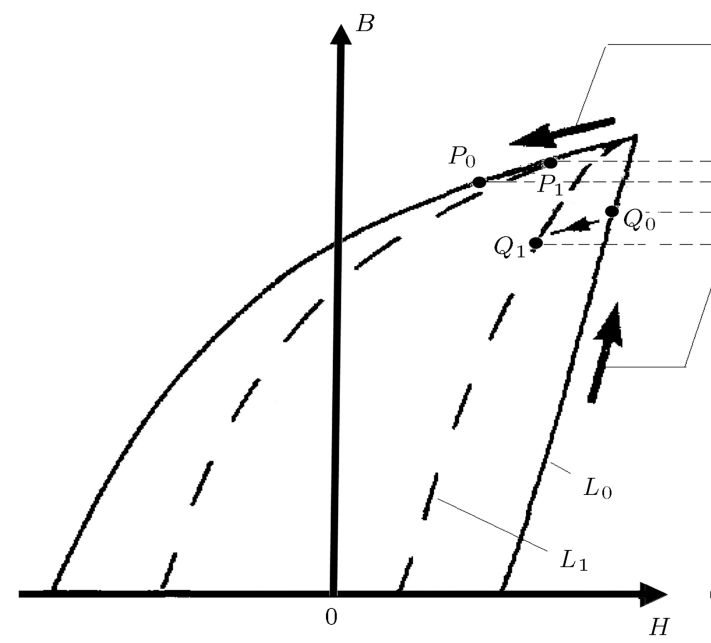

(a)

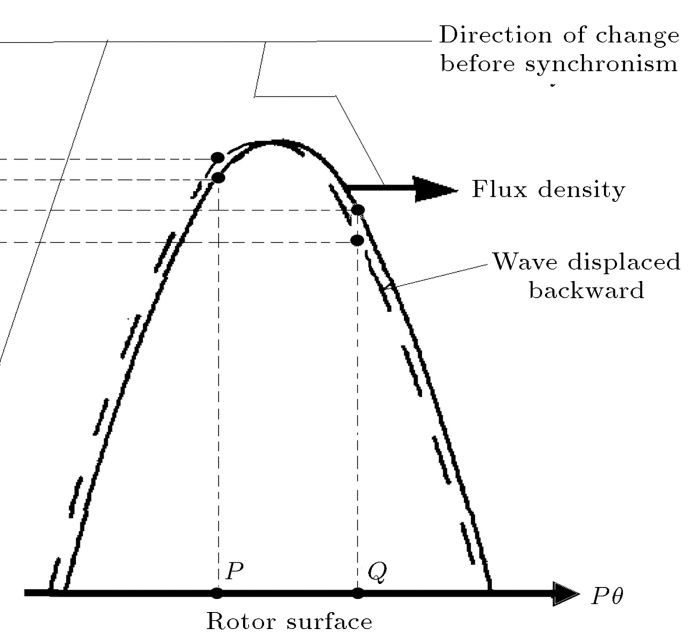

(b)

Figure 8. $B-H$ loops and flux density waves for two different loads [13] ( $L_{1}$ loop corresponds to the lower load).

When the motor reaches its synchronous speed, magnetic state momentarily stops changing at any point. For example, the magnetic state at point $P$ in Figure 8(b) in the rotor stops at the location of $P_{0}$ on the loop shown in Figure 8(a), and the magnetic state at another point stops at $Q_{0}$ on the same loop. If the load torque is equal to the output torque, $T_{e m}$, the motor speed will not change further. On the other hand, if the load torque is less than $T_{e m}$, the motor speed will increase further and a displacement of the rotor forward with respect to the rotating flux density wave will occur. So, the points of $P_{0}$ and $Q_{0}$ come to $P_{1}$ and $Q_{1}$, which means that the operational $B-H$ loop goes to other loop $L_{1}$. Hence, a new $B-H$ loop is created whose area is smaller than loop $L_{0}$. It means that with changing load torque, the $B-H$ loop will not be fixed. The same behavior can be explained when the load torque increases, so that loop $L_{1}$ will be wider than loop $L_{0}$. The shape of $L_{1}$ is different from the major hysteresis loop created by rated input voltage or from those of the minor hysteresis loops created by lower voltages. Since the area of the $B-H$ loop is proportional to the output torque [16], the area of loop $L_{1}$ is proportional to output torque witch is in equilibrium with load torque. With the above deduction, a new search algorithm to identify correct hysteresis lag angle $\beta$ based on the input stator voltage and load torque is presented as follows.

\subsection{Calculation of rotor's equivalent circuit parameters}

Hysteresis motor used in this paper is a super-high speed circumferential-flux, 3-phase, star-connected motor, with rated power $60 \mathrm{~W}, 60,000 \mathrm{rpm}$ whose parameters are given parameters in Table 1 . To develop dynamic model of hysteresis motor, the value of rotor's parameters due to operational hysteresis motor must be calculated. For this purpose, $B-$ $H$ curves of rotor material are firstly measured by some standard experiments [29]. Employed magnetic material used in this study is Vicalloy 2 with typical $B-H$ loops shown in Figure 3. It is a composition of Vanadium-Iron-Cobalt (V13\%-Fe35\%-Co52\%). The maximum achieved output hysteresis torque in steady state corresponds to the maximum applied voltage to stator that is proportional to major hysteresis loop. To simplify calculation, the fundamental harmonic of magnetic field intensity $(H)$ and field density $(B)$ are just considered. In other words, the hysteresis loops are considered elliptical.

The flowchart for calculation of the motor's parameters in air gap and rotor circuit is shown in Figure 9. Firstly, the operational $B-H$ loop or the corresponding lag angle, $\beta$, due to applied stator voltage, $V_{\text {in }}$, is identified, and then it is modified based on applied load torque using equivalent circuit shown in Figure 4. In this circuit, $R_{s}+j X_{l s}$ is stator leakage impedance, $R_{c} \| j X_{m}$ is air gap impedance, and $\left(R_{h}+j X_{h}\right) \| R_{e} / s$ is equivalent rotor impedance.

The air gap reactance and rotor impedance are expressed as [13]:

$$
\begin{aligned}
& X_{m}=\frac{2 m \omega\left(K_{w} N_{p h}\right)^{2} \mu_{0} r_{g} l_{h}}{\pi P^{2} g}, \\
& R_{h}=\frac{m \omega\left(K_{w} N_{p h}\right)^{2} \mu V_{r}}{\pi^{2} r_{h}^{2}} \sin \beta, \\
& X_{h}=\frac{m \omega\left(K_{w} N_{p h}\right)^{2} \mu V_{r}}{\pi^{2} r_{h}^{2}} \cos \beta .
\end{aligned}
$$

To calculate the eddy current resistance in hysteresis material of the rotor, it should be noted that the flux flow in rotor is circumferential and the eddy current 
Table 1. Rated specifications and parameters of used circumferential-flux hysteresis motor.

\begin{tabular}{clcc}
\hline Symbol & \multicolumn{1}{c}{ Quantity } & Value & Dimension \\
\hline$V_{\text {rated }}$ & Line rated voltage & 380 & $\mathrm{~V}$ \\
$T_{\text {rated }}$ & Rated torque & 0.01 & $\mathrm{~N} . \mathrm{m}$ \\
$f_{\text {rated }}$ & Rated frequency & 1000 & $\mathrm{~Hz}$ \\
$\omega$ & Supply angular frequency & $2 \pi \times 1000$ & $\mathrm{rad} / \mathrm{sec}$ \\
$m$ & Number of phase & 3 & - \\
$P$ & Number of poles & 2 & - \\
$J$ & Shaft inertia moment & $3 \times 10^{-4}$ & $\mathrm{~kg} \cdot \mathrm{m}^{2}$ \\
$R_{s}$ & Stator resistance & 60 & $\Omega / \mathrm{ph}$ \\
$R_{c}$ & Stator core loss equivalent resistance & 10580 & $\Omega / \mathrm{ph}$ \\
$R_{h}$ & Rated rotor hysteresis resistance & 360 & $\Omega / \mathrm{ph}$ \\
$R_{e}$ & Eddy current resistance of rotor & 223 & $\Omega / \mathrm{ph}$ \\
$X_{l s}$ & Stator leakage reactance & 78 & $\Omega / \mathrm{ph}$ \\
$X_{m}$ & Rated magnetizing reactance & 165 & $\Omega / \mathrm{ph}$ \\
$X_{h}$ & Rated rotor hysteresis reactance & 190 & $\Omega / \mathrm{ph}$ \\
$l_{h}$ & Axial length of hysteresis ring & 25 & $\mathrm{~mm}$ \\
$g$ & Air gap length & 1 & $\mathrm{~mm}$ \\
$r_{g}$ & Mean radius of air gap & 24.45 & $\mathrm{~mm}$ \\
$\beta$ & Hysteresis lag angle & $52^{\circ}$ & - \\
$\rho$ & Electrical resistivity of hysteresis ring & 650 & $\mu \Omega . \mathrm{mm}$ \\
$\mu_{r}$ & Relative permeability of hysteresis ring & 20 & - \\
$\mu_{0}$ & Permeability of free space & $4 \pi \times 10^{-7}$ & $\mathrm{H} / \mathrm{m}$ \\
\hline & & & \\
\hline
\end{tabular}

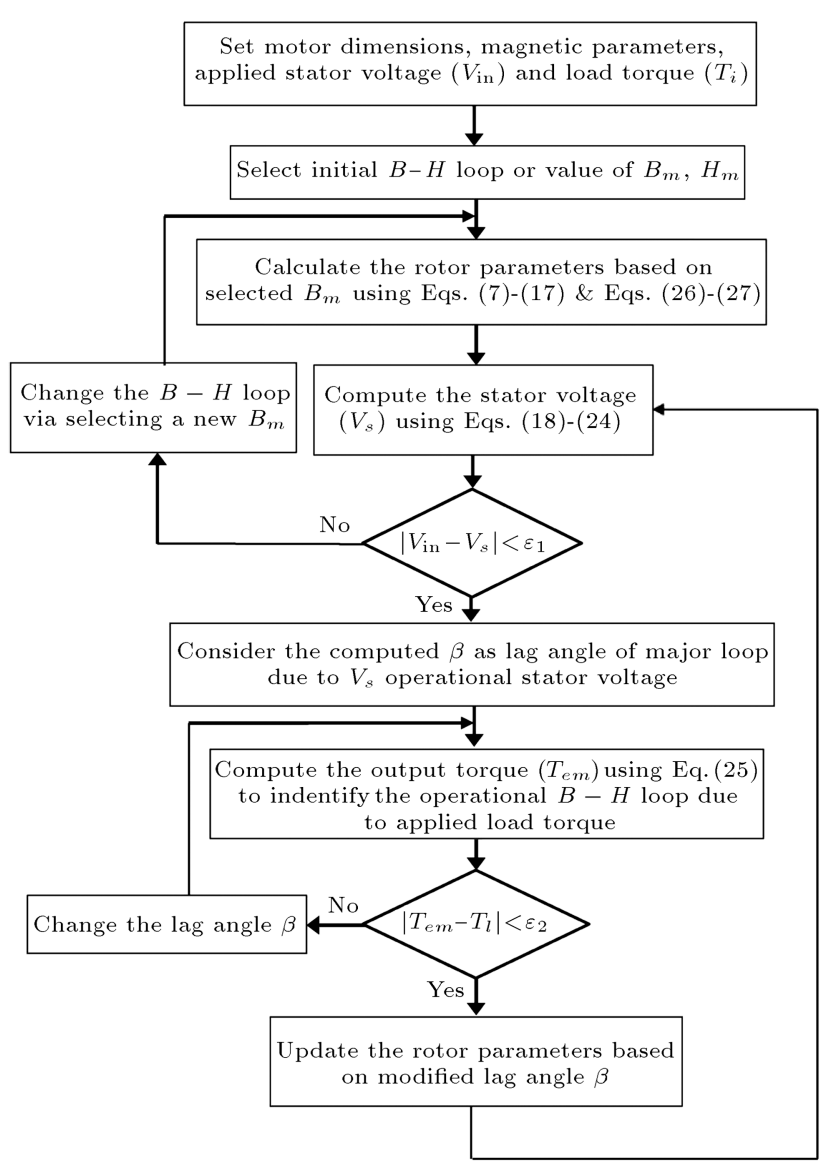

Figure 9. Flowchart for calculation of the rotor's equivalent circuit parameters. vector is perpendicular to the flux. So, eddy current resistance can be obtained from:

$$
R_{e}=\frac{2 \rho l_{h}}{A_{h}}
$$

The hysteresis ring volume, $V_{r}$, and cross sectional area, $A_{h}$, in Eqs. (8)-(10) are calculated as follows:

$$
\begin{aligned}
& A_{h}=2 \pi r_{h} t_{r}, \\
& V_{r}=A_{h} l_{h}=2 \pi r_{h} t_{r} l_{h} .
\end{aligned}
$$

To identify the hysteresis lag angle $\beta$ due to operational stator voltage, $V_{\text {in }}$, firstly, an initial $B-H$ curve (or initial $H_{m}$ and $B_{m}$ ) is chosen. Suppose that the fundamental harmonic of magnetic field intensity in the rotor is defined as:

$$
H=H_{m} \cos \omega t=\left(B_{m} / \mu\right) \cos \omega t .
$$

So, the flux density in the rotor can be expressed as:

$$
B=a \cos \omega t+b \sin \omega t=B_{m} \cos (\omega t-\beta) .
$$

Corresponding to the measured $B-H$ loops, the parameters of $a$ and $b$ can be calculated for any given $H_{m}$ and created $B_{m}$. For an elliptical $B-H$ loop with area of $W_{h}$, the parameter of $b$ is related to $W_{h}$ through:

$$
b=\frac{W_{h}}{\pi H_{m}},
$$


and coefficient ' $a$ ' is derived from:

$$
a=\sqrt{B_{m}^{2}-b^{2}} .
$$

Therefore, the hysteresis lag angle, $\beta$, is obtained by:

$$
\beta=\tan ^{-1}(b / a)
$$

where it varies from $30^{\circ}$ to $60^{\circ}$ for semi-hard magnetic material used in this study. Now, as shown in Figure 9, to obtain lag angle $\beta$, the equivalent circuit's parameters are calculated. To check the validity of $\beta$, the computed input voltage of stator is compared with the real stator voltage. To compute the stator voltage, $V_{s}$, the induced voltage in air gap is calculated as follows:

$$
E_{g}=\sqrt{2} \pi f K_{w} N_{p h} \phi_{g}
$$

where $\phi_{g}$ represents the air gap flux per pole, and is obtained for a cylindrical machine with selected value of $B_{m}$ by:

$$
\phi_{g}=2 K_{s f} l_{h} r_{g} B_{m} .
$$

The stator input current from steady-state equivalent circuit shown in Figure 4 can be obtained from:

$\vec{I}_{s}=\sqrt{\left(\frac{E_{g}}{R_{c}}+\frac{E_{g}}{R_{e} / s}+\frac{E_{g}}{Z_{h}} \cos \beta\right)^{2}+\left(\frac{E_{g}}{X_{m}}+\frac{E_{g}}{Z_{h}} \sin \beta\right)^{2}}$

$$
\angle-\theta_{g} .
$$

The stator phase voltage is considered as reference phasor, and $\theta_{g}$ is the phase difference between $\vec{E}_{g}$ and $\overrightarrow{I_{s}}$ as:

$$
\theta_{g}=\tan ^{-1}\left(\frac{\frac{1}{X_{m}}+\frac{\sin \beta}{Z_{h}}}{\frac{1}{R_{c}}+\frac{1}{R_{e} / s}+\frac{\cos \beta}{Z_{h}}}\right) .
$$

And, the impedance due to hysteresis material is:

$$
Z_{h}=\sqrt{R_{h}^{2}+X_{h}^{2}}
$$

Therefore, the input voltage is calculated by:

$V_{\text {in }}=$

$\sqrt{\left(E_{g} \cos \theta_{g}+Z_{s} I_{s} \cos \theta_{s}\right)^{2}+\left(E_{g} \sin \theta_{g}+Z_{s} I_{s} \sin \theta_{s}\right)^{2}}$, where $Z_{s}$ and $\theta_{s}$ are the stator's impedance and argument as:

$$
Z_{s}=\sqrt{R_{s}^{2}+X_{l s}^{2}}, \quad \theta_{s}=\tan ^{-1}\left(X_{l s} / R_{s}\right) .
$$

The error between calculated input voltage, $V_{\text {in }}$, by Eq. (23) and real stator voltage should be less than $\varepsilon_{1}=0.01 \mathrm{~V}$. Otherwise, the chosen $B-H$ curve changes due to the modification of $H_{m}$ by a proper step size, and the calculations are repeated until the error falls into $\varepsilon_{1}$ tolerance.

As mentioned earlier, when the hysteresis motor reaches synchronous speed, developed torque, $T_{e m}$ is equal to load torque, $T_{l}$. The steady-state developed torque in terms of hysteresis ring's volume, and therefore, operational $B-H$ loop properties and lag angle $\beta$ can be expressed as [1]:

$$
T_{e m}=\frac{m P}{2} \pi\left(B_{m} H_{c}\right) r_{h} t_{r} l_{h} \sin \beta .
$$

It means that if under constant stator voltage, the load torque varies, operational $B-H$ loop changes without changing the value of $B_{m}$ and $H_{m}$, and so the lag angle $\beta$ varies, as shown in Figure 8 . Therefore, in the final stage of computation, the developed torque, $T_{e m}$, through Eq. (12) is compared with the load torque, and lag angle $\beta$ is iterated by a proper step size until the torque difference falls to desired tolerance $\varepsilon_{2}=0.0005$ N.m as shown in Figure 9. The computed lag angle $\beta$ is then used to update the rotor's equivalent circuit parameters.

Hysteresis motors use the semi-hard magnetic materials that, unlike induction motors, induce considerable back-EMF voltage in stator. For example, employed hysteresis motor in this study, with Vicalloy material, induces phase voltage of 100 volts at speed of $1000 \mathrm{~Hz}$. In other words, hysteresis material at synchronous speed acts as a permanent magnet. In [30,31], the current sources have been considered to model the permanent magnet and hysteresis materials. But, for dynamic modeling of hysteresis motor, we consider an induced voltage source in the rotor circuit. This equivalent induced voltage, $E_{h}$, for hysteresis material can be obtained from Figure 4 as shown in Box I.

$$
\vec{E}_{h}=\sqrt{\left(X_{m} I_{s} \sin \theta_{g}+\left(X_{h}+X_{m}\right) I_{h} \sin \beta\right)^{2}+\left(X_{m} I_{s} \cos \theta_{g}+\left(X_{h}+X_{m}\right) I_{h} \cos \beta\right)^{2}} \angle-\theta_{h},
$$

where:

$$
\theta_{h}=\tan ^{-1}\left(\frac{X_{m} I_{s} \cos \theta_{g}+\left(X_{h}+X_{m}\right) I_{h} \cos \beta}{X_{m} I_{s} \sin \theta_{g}+\left(X_{h}+X_{m}\right) I_{h} \sin \beta}\right) .
$$


Calculated $E_{h}$ is a phasor corresponding to phase ' $a$ '. It has to be expressed in time domain for three phases, and then to be transferred to $E_{d h}$ and $E_{q h}$ in $d q$ reference frame. These voltages at synchronous condition are constant.

\subsection{Mathematical model and equivalent circuit of hysteresis motor in rotating $d q$ reference frame}

The hysteresis motor voltage equations in synchronously rotating $d q$ reference frame can be written as:

$$
V_{d q}=R . I_{d q}+\frac{d \Lambda_{d q}}{d t}+E_{d q}
$$

where:

$$
\begin{array}{cc}
V_{d q}=\left[\begin{array}{c}
v_{d s} \\
v_{q s} \\
v_{d r}=0 \\
v_{q r}=0
\end{array}\right], & I_{d q}=\left[\begin{array}{c}
i_{d s} \\
i_{q s} \\
i_{d r} \\
i_{q r}
\end{array}\right], \\
\Lambda_{d q}=\left[\begin{array}{c}
\lambda_{d s} \\
\lambda_{q s} \\
\lambda_{d r} \\
\lambda_{q r}
\end{array}\right], & E_{d q}=\left[\begin{array}{c}
E_{d s} \\
E_{q s} \\
E_{d h} \\
E_{q h}
\end{array}\right],
\end{array}
$$

and:

$$
R=\left[\begin{array}{cccc}
R_{s} & 0 & 0 & 0 \\
0 & R_{s} & 0 & 0 \\
0 & 0 & R_{r} & 0 \\
0 & 0 & 0 & R_{r}
\end{array}\right]
$$

where the rotor resistance is calculated from:

$$
R_{r}=\frac{1}{1 / R_{h}+s / R_{e}},
$$

and ' $s$ ' denotes the slip. The stator and rotor fluxes in Eq. (28) are:

$$
\Lambda_{d q}=L \times I_{d q}=\left[\begin{array}{cccc}
L_{s} & 0 & 0 & 0 \\
0 & L_{s} & 0 & 0 \\
0 & 0 & L_{r} & 0 \\
0 & 0 & 0 & L_{r}
\end{array}\right] \times\left[\begin{array}{c}
i_{d s} \\
i_{q s} \\
i_{d r} \\
i_{q r}
\end{array}\right]
$$

where the inductances are calculated from:

$$
L_{s}=L_{l s}+L_{m}, \quad L_{r}=L_{h}+L_{m} .
$$

The magnetizing and rotor inductances $L_{m}$ and $L_{h}$ can be calculated from Eqs. (7) and (9). Two voltages, $E_{d s}$ and $E_{q s}$, in Eq. (29) are defined by:

$$
E_{d s}=\omega_{r} \lambda_{q s}, \quad E_{q s}=\omega_{r} \lambda_{d s}
$$

Also, $E_{d h}$ and $E_{q h}$ are $d q$ components of induced voltage due to residual magnetizing action of hysteresis material on the rotor obtained by using Eq. (26) as
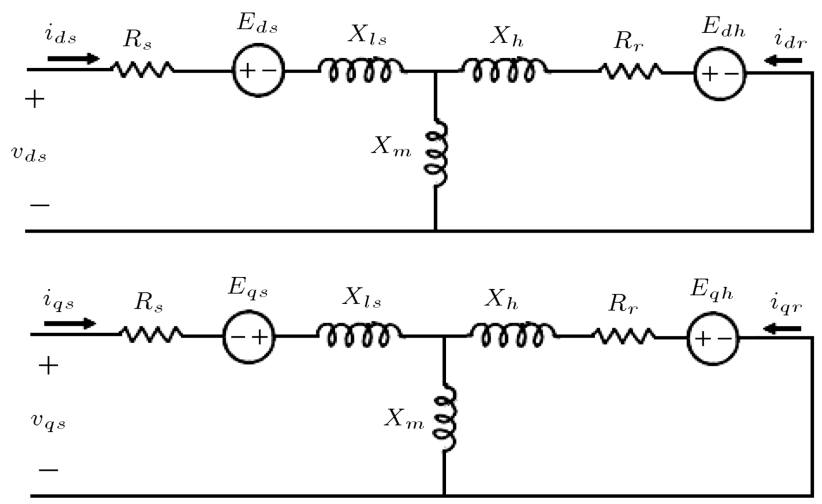

Figure 10. Equivalent circuit for dynamic model of hysteresis motor in rotating $d q$ reference frame.

follows:

$$
\left[\begin{array}{c}
E_{d h} \\
E_{q h}
\end{array}\right]=\left[T_{d q}\left(\theta_{r}\right)\right]\left[\begin{array}{c}
E_{h} \sin \omega t \\
E_{h} \sin \left(\omega t-120^{\circ}\right) \\
E_{h} \sin \left(\omega t+120^{\circ}\right)
\end{array}\right]
$$

The following Park matrix is used for abc to $d q$ transformation [32]:

$\left[T_{d q}\left(\theta_{r}\right)\right]=\frac{2}{3}\left[\begin{array}{ccc}\cos \theta_{r} & \cos \left(\theta_{r}-120^{\circ}\right) & \cos \left(\theta_{r}+120^{\circ}\right) \\ \sin \theta_{r} & \sin \left(\theta_{r}-120^{\circ}\right) & \sin \left(\theta_{r}+120^{\circ}\right) \\ \frac{1}{2} & \frac{1}{2} & \frac{1}{2}\end{array}\right]$.

Developed electromagnetic torque can be expressed in terms of flux and current as:

$$
T_{e m}=\frac{3}{2} \frac{P}{2}\left(\lambda_{d s} i_{q s}-\lambda_{q s} i_{d s}\right) .
$$

And, the mechanical speed is obtained from:

$$
J \frac{d \omega_{r}(t)}{d t}=T_{e m}-T_{l}
$$

The foregoing equations can be summarized in the equivalent circuit model as shown in Figure 10.

\section{Simulation results}

Developed dynamic model is simulated for a true hysteresis motor with summarized parameters in Table 1. It should be noted that employed hysteresis motor in this study is a super high-speed motor with a rated speed of $60,000 \mathrm{rpm}$ whose start-up procedure from zero to final speed takes $4200 \mathrm{sec}$ with a slow acceleration rate. Simulation of this duration takes a considerable computation and needs a lot of RAM and memory capacities. Therefore, to shorten the simulation time to $2 \mathrm{sec}$, we are forced to decrease the inertia moment adequately. Simulations are carried out in different cases: rated load, variable load, variable stator voltage, and variable reference frequency. For the sake of clarification, some of quantities are given 
in per unit scale. The predominant load of employed hysteresis motor is rotational friction as $T_{l}=B_{f} \cdot \omega_{m}^{2}$ that the value of $B_{f}$ is 1 in per unit scale. However, in some cases, an extra constant load at synchronous speed is applied to hysteresis motor.

Figures 11-13 show the simulation results of hysteresis motor during start-up with open-loop $V / f$ scalar control scheme. In addition to rotational friction load, a constant load is applied. Figure 11 shows the applied reference frequency and the applied stator
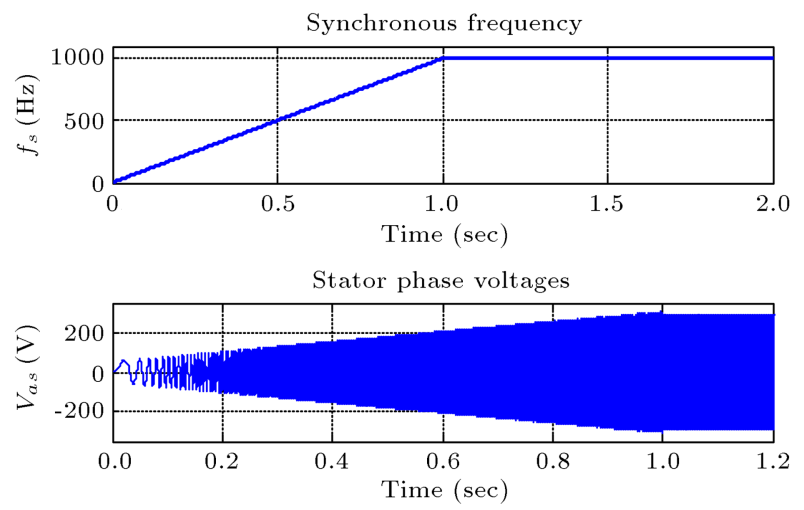

Figure 11. Reference frequency and applied phase voltage to hysteresis motor during open-loop $V / f$ scheme start-up. phase voltage. In Figure 12, the speed and torque motor responses are depicted during startup. The speed reaches synchronous speed under friction and constant load. The speed tracking error during startup is at most $0.5 \%$ and becomes zero at steady-state. Moreover, when a constant load torque $0.5 \mathrm{pu}$ is applied in $1.5 \mathrm{sec}$, the motor can reach synchronous speed after some oscillations.

The RMS current, input power, and power factor waveforms are shown in Figure 13. The current under rated torque $1 \mathrm{pu}$ at steady state $(t=1.4 \mathrm{sec})$ is $0.36 \mathrm{~A}$ (close to actual current of the motor in experiment). When the load torque increases to $1.5 \mathrm{pu}$, the current increases small value and reaches to $0.38 \mathrm{~A}$. It is in accordance with the behavior of an actual hysteresis motor. The input power of the motor at steady state which is $66.69 \mathrm{~W}$ includes output power and stator's copper, and core losses. With increasing the load torque, the power also increases to $50 \%$. Also the power factor is initially 0.278 and after $1.5 \mathrm{sec}$, increases to 0.44 . All simulation data in steady state are in accordance with captured experimental results given later.

In Figure 14, the variations of hysteresis lag angle and rotor parameters are displayed. The angle $\beta$ increases just as the stator voltage increases during $V / f$, and after $1 \mathrm{sec}$, it converges to $50^{\circ}$. Also, at
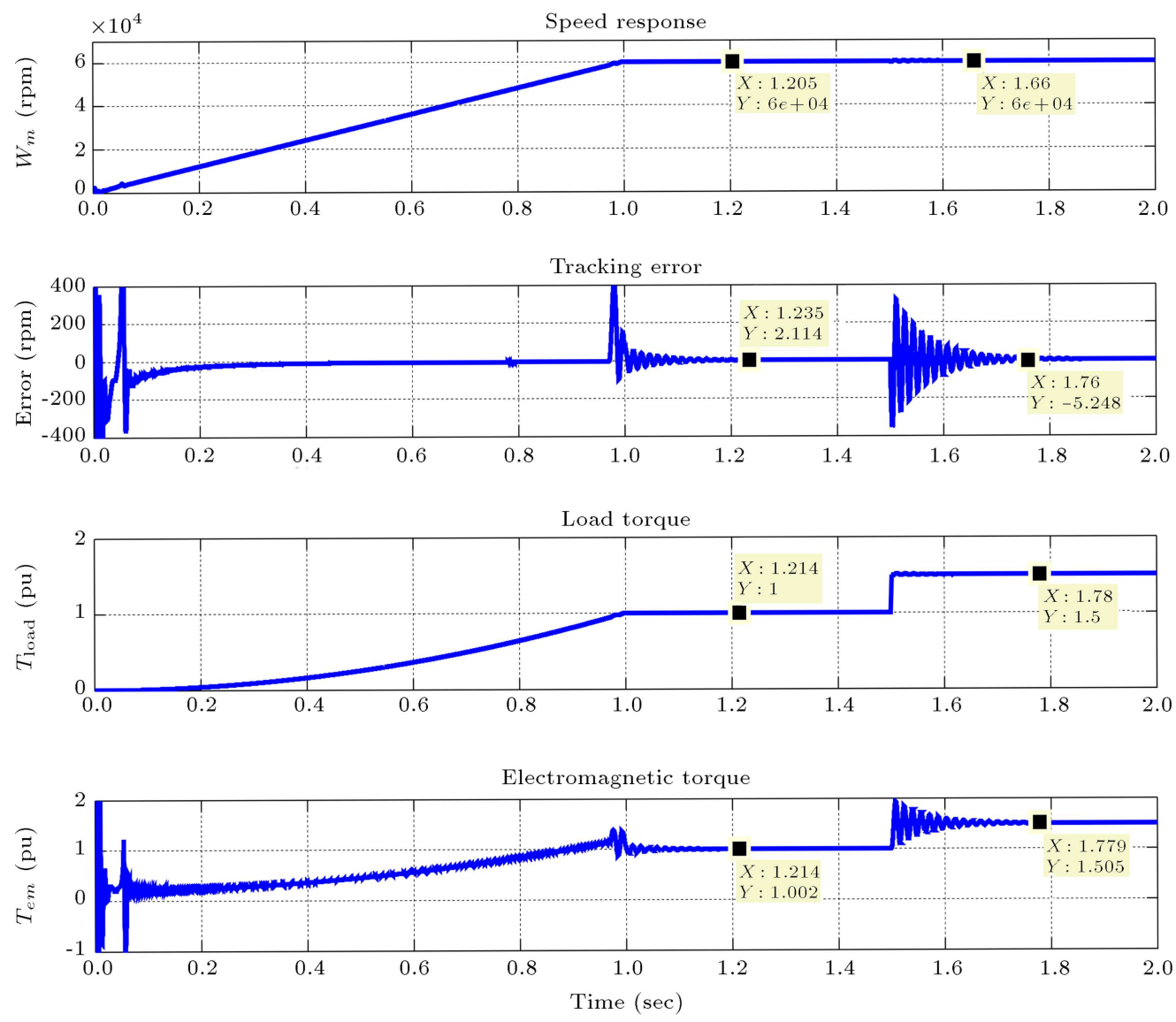

Figure 12. Speed and torque response of hysteresis motor during open-loop $V / f$ scheme start-up. 

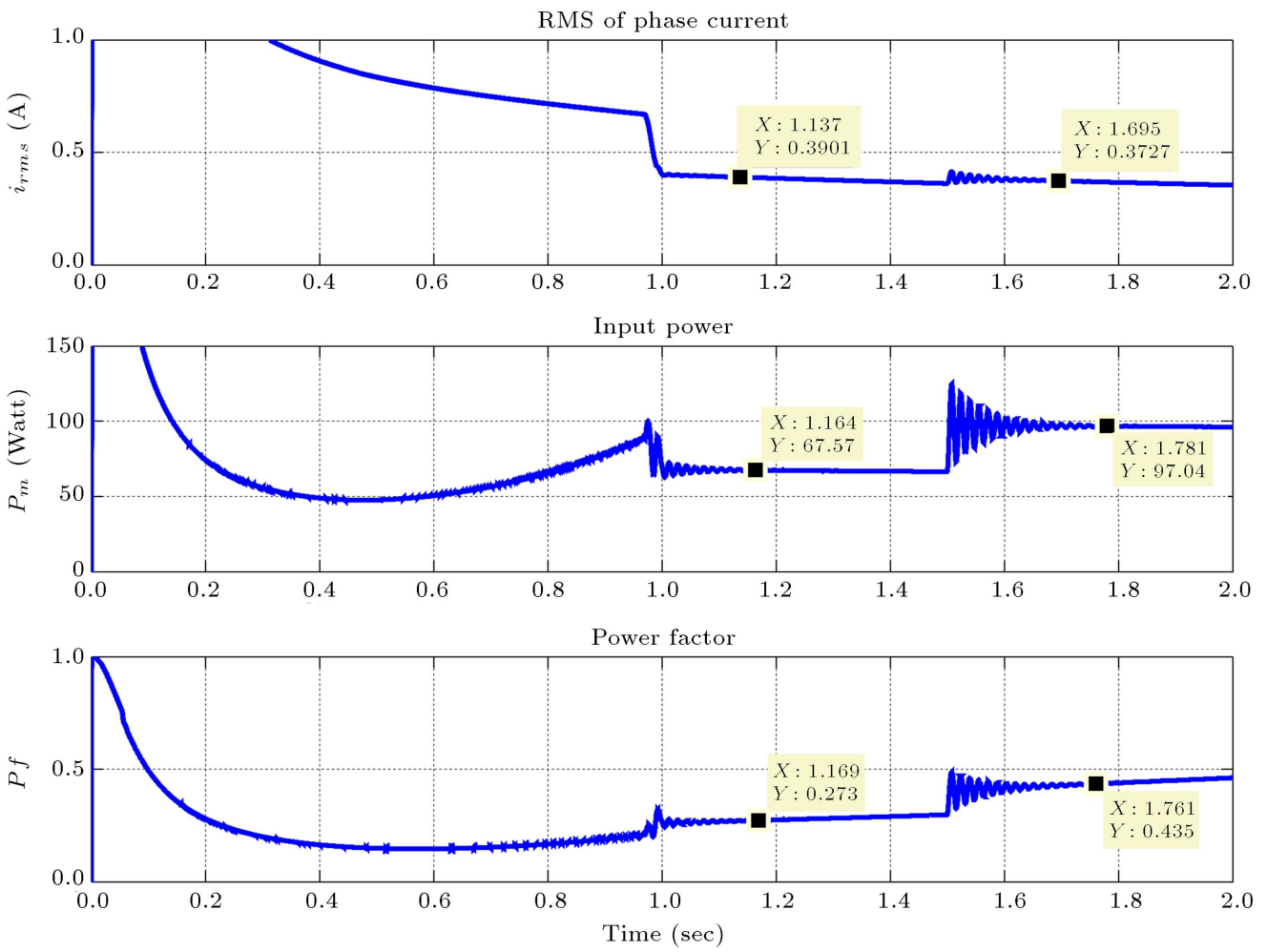

Figure 13. RMS current, input power, and power factor of hysteresis motor during open-loop $V / f$ scheme start-up.
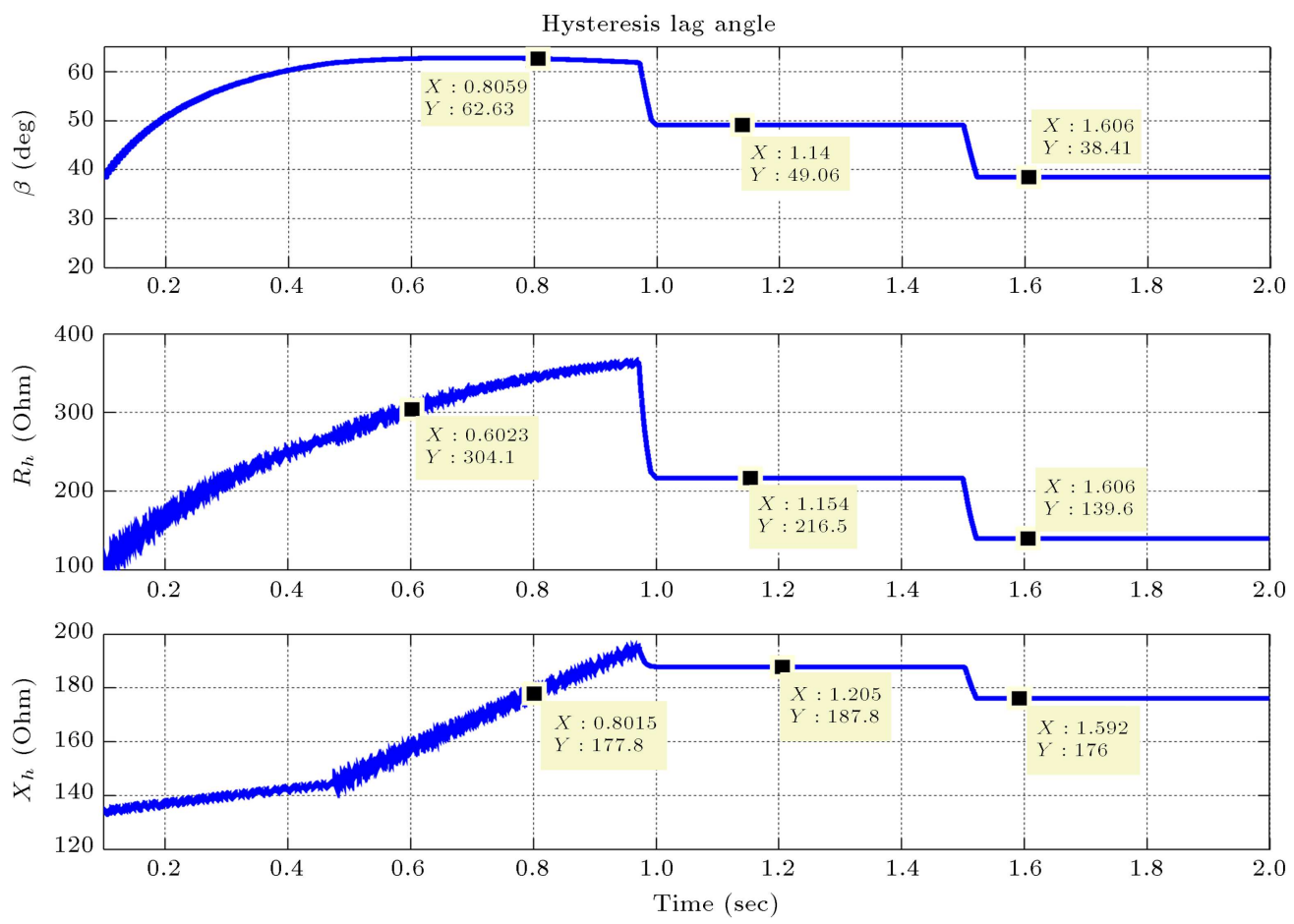

Figure 14. Variations of hysteresis lag angle $\beta$ and $R_{h}$ and $X_{h}$ of rotor.

a time duration of $1.5 \mathrm{sec}$ and after increasing the load torque, it converges to a higher value of $55^{\circ}$. It means that during startup or load changing, the operational $B-H$ loop continuously changes and finds corresponding $B-H$ loop after 1 sec when the voltage and speed become constant. Moreover, the values of $R_{h}$ and $X_{h}$ are changing with $\beta$ through Eqs. (8) and (9). To supply hysteresis motor in variable-speed applications, power frequency inverter is used. High order harmonics caused by PWM switching lead to 


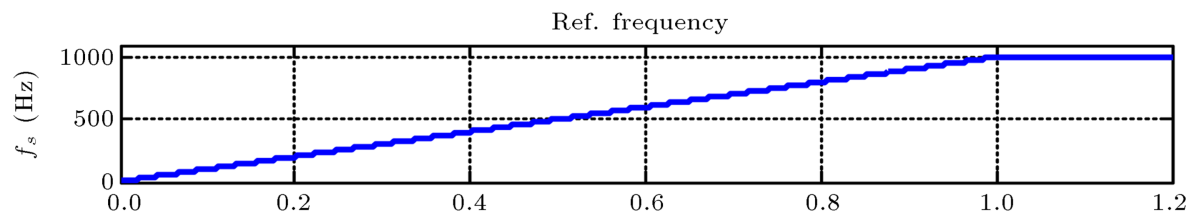

Line voltage
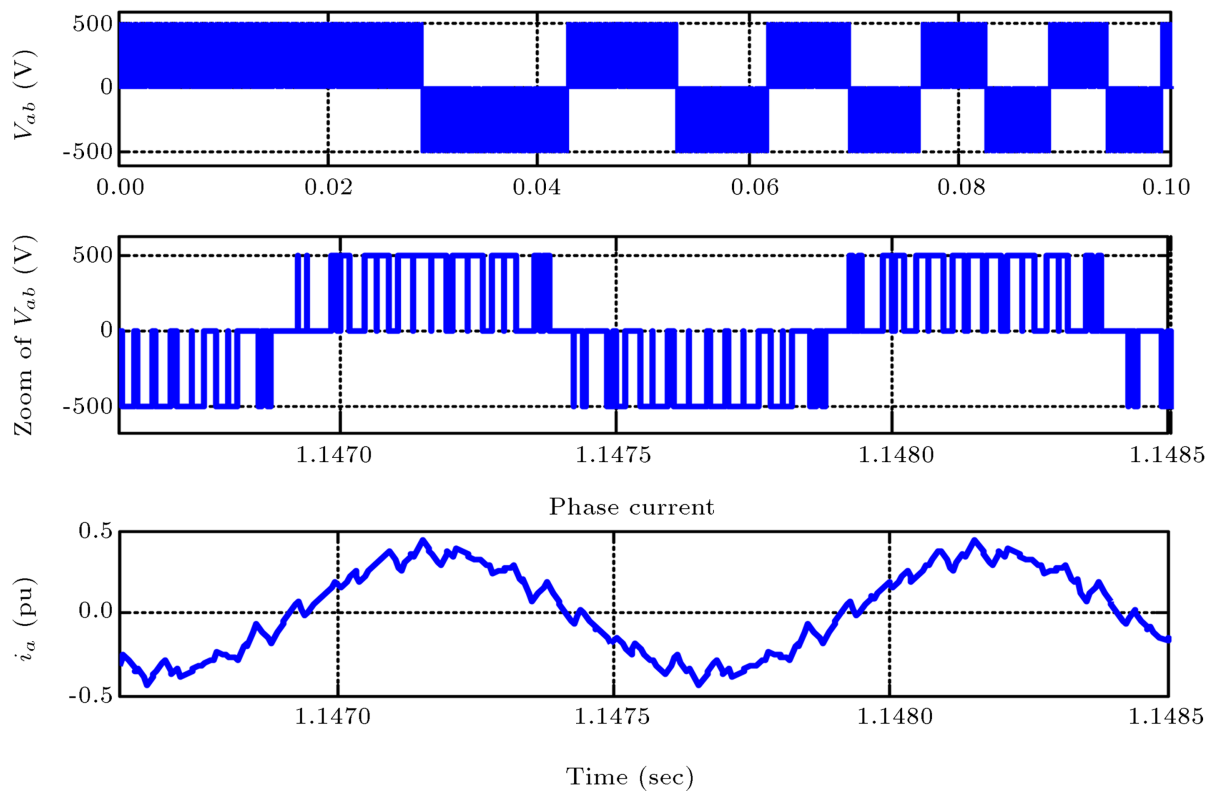

Figure 15. Line voltage and phase current of hysteresis motor during $V / f$ startup using PWM inverter.
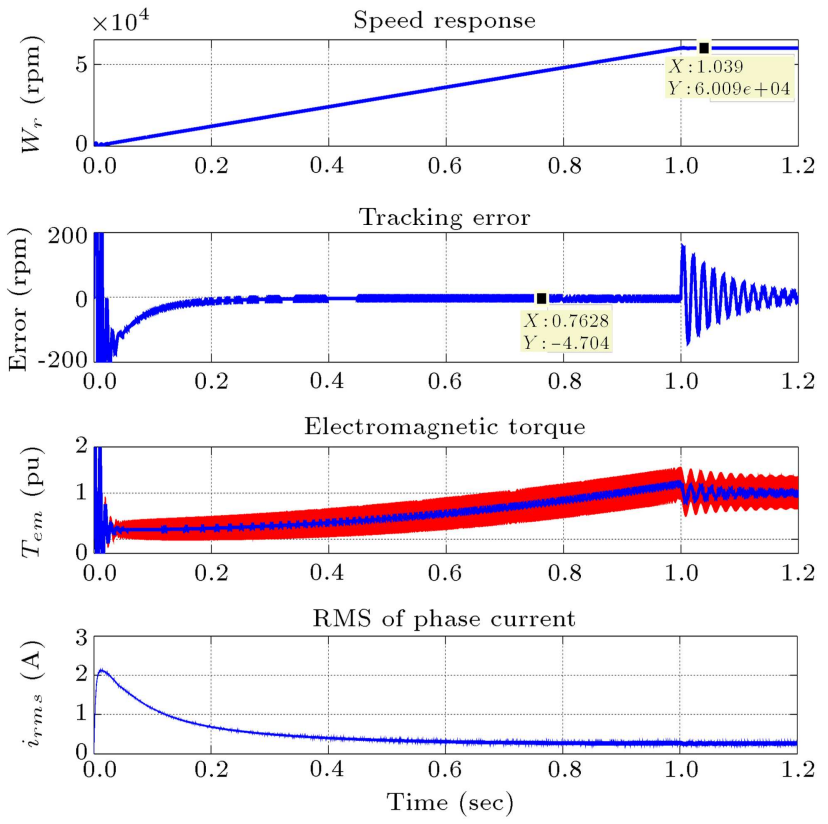

Figure 16. Speed and torque response of hysteresis motor during $V / f$ startup using PWM inverter.

high frequency ripple in torque. Figures 15 and 16 show the simulation results while a PWM inverter is used to supply hysteresis motor. Switching frequency is set to $15 \mathrm{kHz}$, and DC bus voltage is $500 \mathrm{~V}$. Applied PWM voltage based on $V / f$ start-up as well as the motor current are shown in Figure 15. FFT analysis of voltage and currents yields their corresponding THD values which are $71 \%$ and $14 \%$, respectively. Figure 16 displays speed and torque response. Torque waveform includes high frequency ripples about $50 \%$ due to current's harmonics; however, it cannot bring about fluctuations in the motor speed.

The performance of hysteresis motor during sequential acceleration/deceleration that is usual for some applications is studied as follows. The speed and torque waveforms of the motor are shown in Figure 17. The supply frequency and motor speed increase to 30,000 and $60,000 \mathrm{rpm}$, and then decrease to $18,000 \mathrm{rpm}$, and finally to zero. Also, the variations of hysteresis lag angle and the equivalent circuit's parameters of the rotor are illustrated in Figure 18 during this test. Unfortunately, due to no access to a suitable data acquisition set, experimental results of transient cannot be derived accurately. Moreover, as it was mentioned earlier, simulation results are carried out in a short time scale, whereas the presented tests are carried out in long-time duration (more than one hour) in the experiment. Therefore, only some steadystate experimental results were measured. When the motor works with nominal line voltage of $380 \mathrm{~V}$ under nominal friction load, experimental results for current, power factor, and input power are $0.34 \mathrm{~A}$, 0.29 , and $63 \mathrm{~W}$, respectively. Corresponding values 

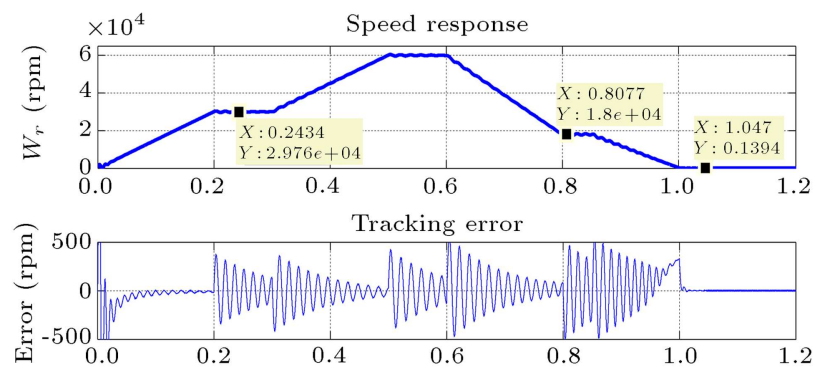

Electromagnetic torque
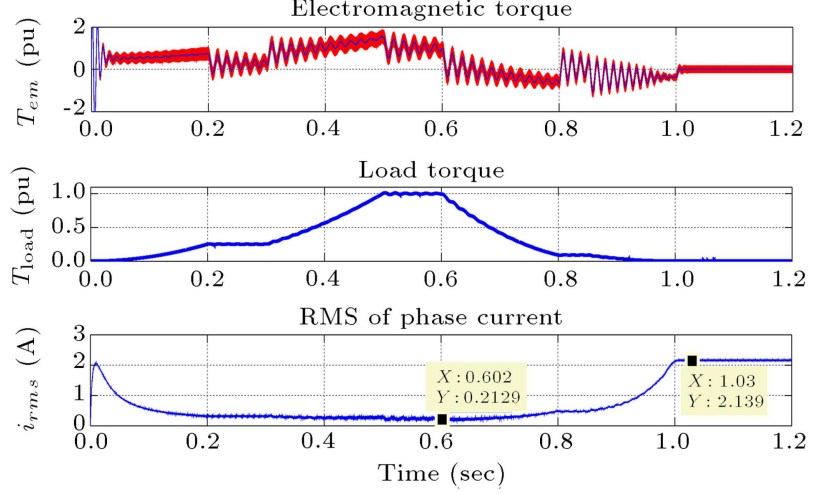

Figure 17. Speed and torque response of hysteresis motor in sequential acceleration/deceleration using PWM inverter.
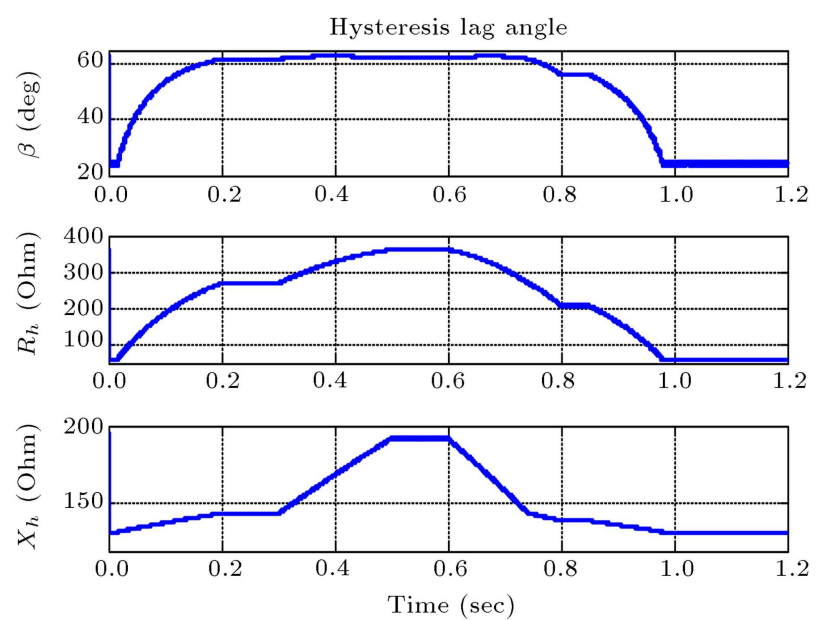

Figure 18. Variations of hysteresis lag angle $\beta$ and $R_{h}$ and $X_{h}$ of the rotor during sequential Acc./Dec. test.

in simulations from Figure 13 are $0.36 \mathrm{~A}, 0.27$, and $66 \mathrm{~W}$. They are in good agreement with experimental results. Figure 19 shows the phase current, line voltage waveforms, and their FFT analysis in experiment during 1 sec in steady-state. Also, in Figure 20, the average values of motor quantities in experiment and in steady-state for $1 \mathrm{sec}$ are shown. The variations of quantities are resulted from hunting.

\section{Conclusion}

A dynamic model of a high-speed, circumferential-flux hysteresis motor was developed and implemented in
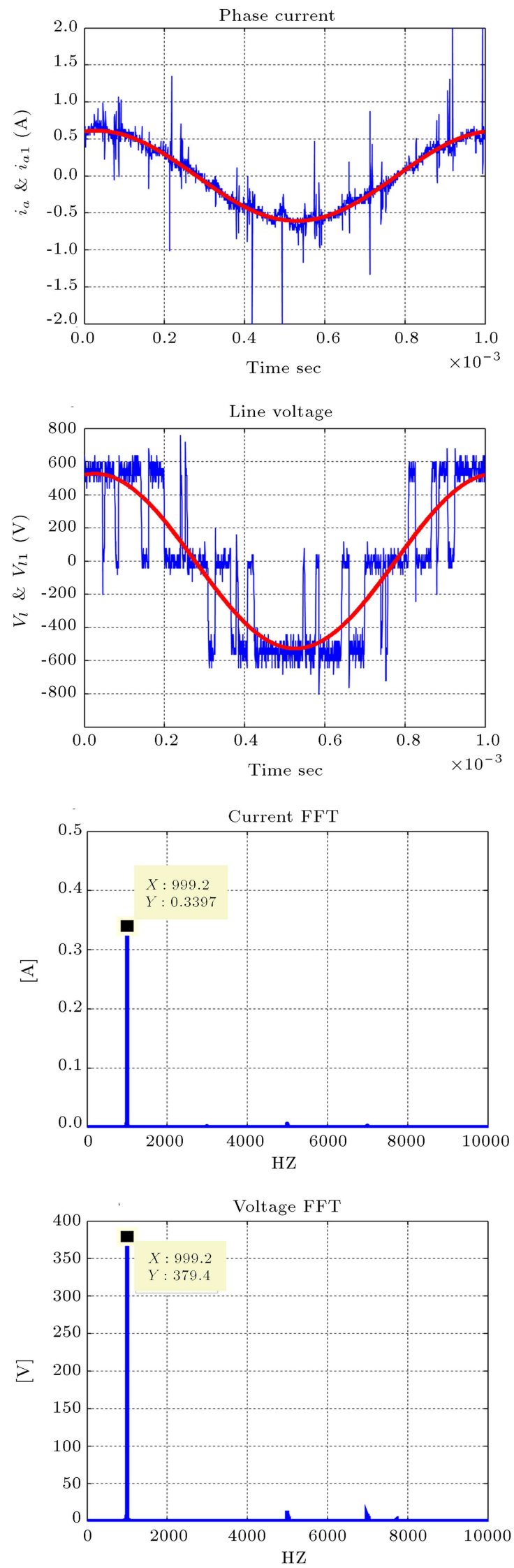

Figure 19. The phase current and line voltage of hysteresis motor in experiment at steady-state condition. 

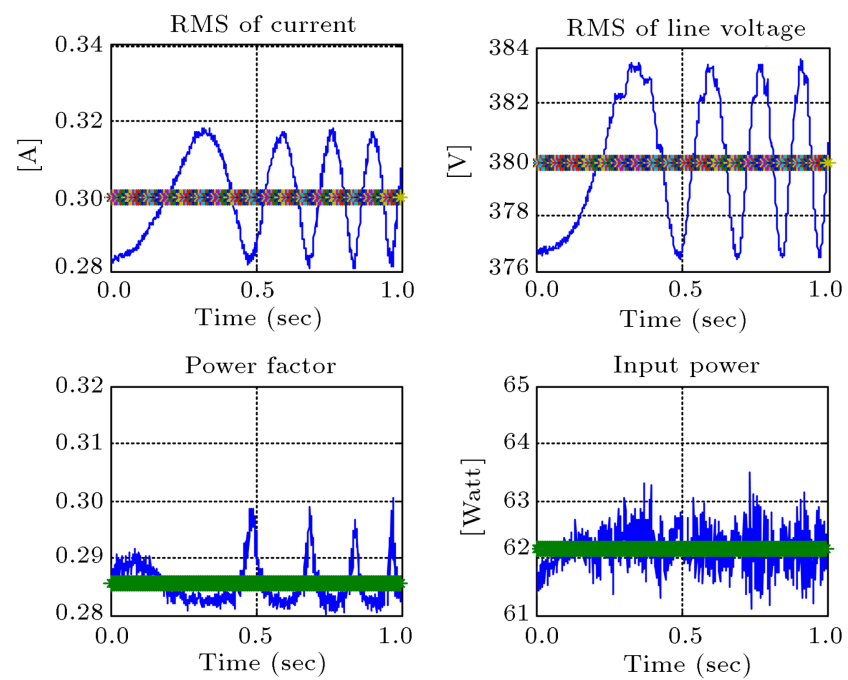

Figure 20. The average value of phase current, line voltage, power factor, and input power of hysteresis motor in experiment in steady state.

Matlab/Simulink. In the developed model, a linear time varying equivalent circuit was suggested for the rotor as a series of inductive impedance and dependent voltage source. It is adapted according to variations of load torque and stator voltage. The major advantage of this model over the old adaptive models is the consideration of properties of $B-H$ loop, such as $B_{r}$, $H_{c}, B_{m}$, and $H_{m}$, to determine the hysteresis lag angle $\beta$. The developed dynamic model was simulated in $V / f$ startup based on change in load torque and frequency tracking with real PWM inverter. Simulation results are confirmed with experimental results just in steadystate. The developed model can predict almost all important aspects of hysteresis motor operation theory. The proposed dynamic model can be used for closedloop control, estimation and identification of motor's speed, fault diagnosis, optimum design, and sensitivity analysis.

\section{References}

1. Rahman, M.A. and Osheiba, A.M. "Dynamic performance prediction of poly phase hysteresis motors", IEEE Trans. on Industry Applications, 26(6), pp. 1026-1033 (1990).

2. Roters, C.H. "The hysteresis motor-advances which permit economical fractional horsepower ratings", Trans. of the American Institute of Electrical Engineers, 66(1), pp. 1419-1430 (1947).

3. Patterson, D.J., Colton, J.L., Mularcik, B., Kennedy, B.J., Camilleri, S. and Rohoza, R. "A comparison of radial and axial flux structures in electrical machines", IEEE Int. Electric Machines and Drives Conf. (IEMDC), pp. 1029-1035 (2009).

4. Nitao, J.E., Scharlemann, T. and Kirkendall, B.A. "Equivalent circuit modeling of hysteresis motors",
U.S. Department of Energy by Lawrence Livermore National Laboratory, Report no. LLNL-TR-416493 (2009).

5. Modarres, M., Vahedi, A. and Ghazanchaei, M. "Study on axial flux hysteresis motors considering airgap variation", Journal of Electromagnetic Analysis \& Applications, 2, pp. 252-257 (2010).

6. Modarres, M. and Kwon, B. "Rotor design to improve dynamic performance of axial flux hysteresis motors", IET Electric Power Applications, 9(1), pp. 44-49 (2015).

7. Ghanbari, T., Sanati Moghadam, M. and Darabi, A. "Comparison between coreless and slotless kinds of dual rotor discs hysteresis motors", IE T Electric Power Applications, 10(2), pp. 133-140 (2016).

8. Nasiri-Zarandi, R., Mirsalim, M. and Tenconi, A. "A novel hybrid hysteresis motor with combined radial and axial flux rotors", IEEE Trans. on Industrial Electronics, 63(3), pp. 1684-1693 (2016).

9. Halvaei Niasar, A., Zare, M. and Moghbelli, H. "Dynamic modeling and simulation of a super-highspeed circumferential-flux hysteresis motor", Journal of Engineering, 2013, Article ID 898634, pp. 1-7 (2013).

10. Modarres, M., Vahedi, A. and Ghazanchaei, M. "Effect of air gap variation on characteristics of an axial flux hysteresis motor", IEEE Int. Conf. on Power Electronic \& Drive Systems \& Technologies, pp. 323328 (2010).

11. Nasiri-Zarandi, R. and Mirsalim, M. "Analysis and torque calculation of an axial flux hysteresis motor based on hyperbolic model of hysteresis loop in Cartesian coordinates", IEEE Trans. on Magnetics, 99(1), Article \#: 8105710 (2015).

12. Ishikawa, T. and Kataoka, T. "V curve of hysteresis motor", IEE Proceedings-B, Electric Power Applications, Electric Power Applications, 138(3), pp. 137141 (1991).

13. Kataoka, T., Ishikawa, T. and Takahashi, T. "Analysis of a hysteresis motor with overexcitation", IEEE Trans. on Magnetics, 18(6), pp. 1731-1733 (1982).

14. Heck, C., Magnetic Materials and Their Applications, Butterworth \& Co. Publisher Ltd. (1974).

15. Jackson, R.D., Rahman, M.A. and Slemon, G.R. "Analysis and determination of ring flux distribution in hysteresis motors", IEEE Trans. on Power Apparatus and Systems, 102(8), pp. 2743-2749 (1983).

16. Teare, B.R. "Theory of hysteresis motor torque", AIEE Trans., 59, pp. 907-912 (1940).

17. Miyairi, S. and Kataoka, T. "A basic equivalent circuit of the hysteresis motor", IEE Journal, Japan, 85, pp. 41-50 (1965).

18. Robertson, S.D.T. and Zaky, S.Z.G. "Analysis of the hysteresis machine-part-I", IEEE Trans. on Power Apparatus and Systems, 88, pp. 474-483 (1969). 
19. Copeland, M.A. and Slemon, G.R. "An analysis of the hysteresis motor: part-I-analysis of the idealized machine", IEEE Trans. on Power Apparatus and System, 82(65), pp. 34-42 (1963).

20. Copeland, M.A. and Slemon, G.R. "An analysis of the hysteresis motor: part-II-the circumferential-flux machine", IEEE Trans. on Power Apparatus and Systems, 83(6), pp. 619-625 (1964).

21. Rahman, M.A. "Analytical models for poly phase hysteresis motor", IEEE Trans. on Power Apparatus and Systems, 92(1), pp. 237-242 (1973).

22. Zare, M. and Halvaei Niasar, A. "A novel sensorless vector control of hysteresis motor drive", 4th IEEE Power Electronics, Drive Systems \& Technologies Conf. (PEDSTC), pp. 261-264 (2013).

23. Halvaei Niasar, A., Moghbelli, H. and Yavari, M. "Speed sensorless control of hysteresis motor based on MRAS and Luenberger observer techniques", 19th Int. Conf. on Neural Information Processing (ICONIP'12), Part V, LNCS 7667, pp. 455-464 (2012).

24. Badeeb, O.M. "Investigation of the Dynamic performance of hysteresis motors using MATLAB/ SIMULINK", Journal of Electrical Engineering, 56(34), pp. 106-109 (2005).

25. Rahman, M.A. and Qin, R. "A permanent magnet hysteresis hybrid synchronous motor for electric vehicles", IEEE Trans. on Industrial Electronics, 44(1), pp. 4653 (1997).

26. Rabbi, S.F. and Rahman, M.A. "Analytical modeling of a hysteresis interior permanent magnet motor", IEEE Int. Conf. on Electrical Machines (ICEM), pp. 2612-2617 (2014).

27. Darabi, A. and Lesani, H. "Modeling and optimum design of disk-type hysteresis motors", IEEE Int. Conf. on Electrical Machines and Systems (ICEMS), pp. 9981002 (2007).

28. Darabi, A., Ghanbari, T., Rafiei, M., Lesani, H. and Sanati-Moghadam, M. "Dynamic performance analysis of hysteresis motors by a linear time-varying model",
Iranian Journal of Electrical \& Electronic Engineering, 4(4), pp. 202-215 (2008).

29. "IEEE standard for test procedures for magnetic cores", IEEE Std. 393-1991, American National Standard (ANSI) (1991).

30. Qian, J. and Azizur Rahman, M. "Analysis of field oriented control for permanent magnet hysteresis synchronous motors", IEEE Trans. on Industry Applications, 29(6), pp. 1156-1163 (1996).

31. Rabbi, S.F. and Rahman, M.A. "Equivalent circuit modeling of an interior permanent magnet hysteresis motor", IEEE Canadian Conf. on Electrical and Computer Engineering (CCECE), p. 15 (2014).

32. Ong, C.M., Dynamic Simulations of Electric Machinery, Prentice-Hall Inc. (1998).

\section{Biography}

Abolfazl Halvaei Niasar (S'04-M'06-SM'14) was born in Kashan, Iran, in 1974. He received his BSc, MSc, and $\mathrm{PhD}$ in 1996, 1999, and 2008 from Isfahan University of Technology (IUT), University of Tehran (UT), and Iran University of Science and Technology (IUST), respectively, all in Electrical Engineering.

He joined the Department of Electrical and Computer Engineering in University of Kashan, Kashan, Iran since 2008 as an Assistant Professor. He has authored more than 80 technical papers published in journals and conference proceedings. He is the holder of two Iranian patents and has directed some industrial research projects so far. His current major research interests include PM and brushless DC motor (BLDC) drives, sensorless drives, design, analysis, and control of electrical machines, development of Electric Vehicles (EVs) and Hybrid Electric Vehicles (HEVs), DSPbased control systems and industrial control systems engineering. Dr. Halvaei is a senior member of the Institute of Electrical and Electronics Engineers, IEEE. 